DOI 10.37882/2223-2982.2021.01.26

\title{
ПРИМЕНЕНИЕ МЕТОДА ЛИЧНОЙ БЕСЕДЫ РУКОВОДИТЕЛЯ ШКОЛЫ С УЧАЩИМИСЯ ДЛЯ РАЗВИТИЯ АКАДЕМИЧЕСКОЙ САМООЦЕНКИ, МОТИВАЦИИ И ДОСТИЖЕНИЙ УЧЕНИКОВ
}

\begin{abstract}
APPLICATION OF THE METHOD OF PERSONAL CONVERSATION BETWEEN STUDENTS AND THE HEAD OF SCHOOL TO DEVELOP STUDENTS' ACADEMIC SELF-ESTEEM, MOTIVATION AND STUDENT ACHIEVEMENT
\end{abstract}

K. Raissova A. Akhmetova

Summary: This article describes the method of personal conversation between director and the students of the school approbated in NIS in Ust-Kamenogorsk, NIS in Petropavlovsk and in NIS in Almaty. The article reflects the main stages of conducting individual meetings between director, students and their legal representatives, which were formed on the basis of long-term school leadership experience. The work presents feedback analysis from students and parents, as well as the achievements of NIS in Ust-Kamenogorsk graduates owing to the method of personal conversation.

Keywords: method of personal conversation, conversation between student and principal, student motivation, the role of interaction between students and academic staff, student achievements, academic self-esteem, individual educational route, NIS experience.
Раисова Кульфарида Бабагумаровна

К.nсх.н., директор, «Центр Педагогического Мастерства», Усть-Каменогорск, Казахстан raisova_k@cpm.kz

Ахметова Анара Кайратовна

Учитель, Назарбаевская Интеллектуальная школа, Усть-Каменогорск, Казахстан akhmetova_a@ukk.nis.edu.kz

Аннотация: Данная статья описывает метод личной беседы директора с учениками школы аппробированный в Назарбаевской Интеллектуальной школе (НИШ) г. Усть-Каменогорск, в НИШ г. Петропавловск и в НИШ г. Алматы. Статья отражает основные этапы проведения индивидуальных встреч директора с учениками и его законными представителями, которые были сформированы на основе многолетнего опыта руководства школой. В работе предоставлены результаты обратной связи учеников и родителей а также достижения выпускников на примере НИШ г. Усть-Каменогорск благодоря методу личной беседы.

Ключевые слова: метод личной беседы, беседа ученика и директора, мотивация ученика, роль взаимодействия ученика и академического персонала, достижения учеников, академическая самооценка, индивидуальный образовательный маршрут, опыт НИШ.

на основе многолетнего опыта руководства школой, в Назарбаев Интеллектуальной школе (НИШ) г. УстьКаменогорск в 2011 году был разработан метод личной беседы директора школы с учащимся. Помимо НИш г. Усть-Каменогорск данный метод был аппробирован в НИШ г. Петропавловск и в НИШ г. Алматы на протяжении 8 лет.

Метод личной беседы, заключается во встрече директора школы с учеником и его законными представителями. В данной встрече обязательно присутствие куратора, профориентатора, психолога и школьного врача. Личная беседа директора с каждым учеником, как правило, проводится четыре раза в течение обучения в НИШ (Рис. 1.).

Прием в НИШ во многих городах осуществляется с 7 класса на основе конкурсного отбора. Этапы тестирований предусматривают отбор талантливых и одаренных детей способных обучаться по образователь- 


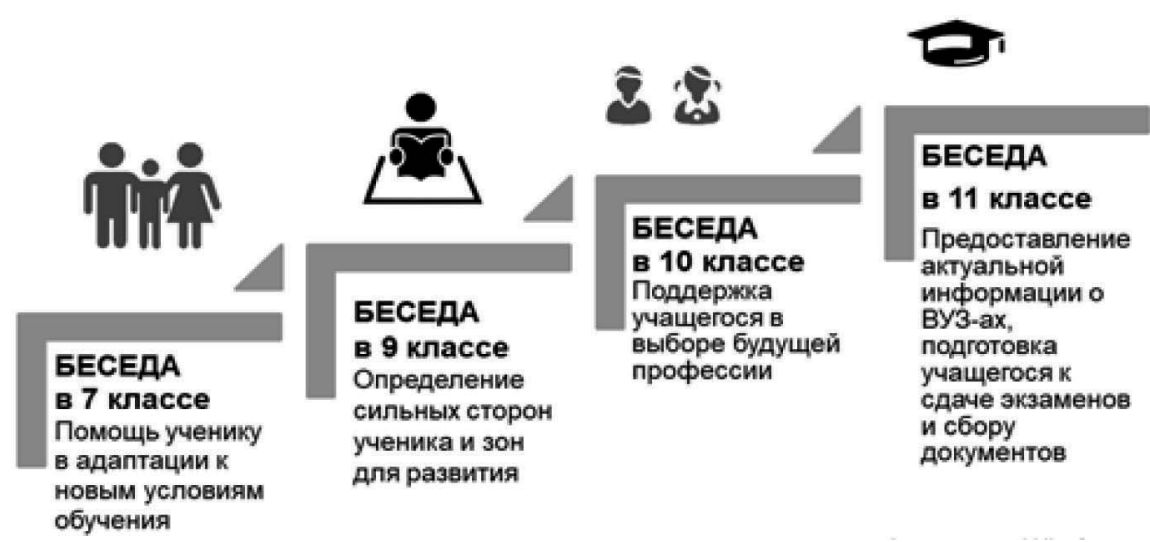

Рис. 1. Периодичность и цели беседы директора с учениками

ной программе НИШ, которая во многом отличается от программы общеобразовательных школ Казахстана. Так как программа ориентированна на углубленное изучение естественно-математических дисциплин и трехъязычную политику, вновь поступившим учащимся необходима помощь в адаптации к новым условиям обучения.

Помимо общих собраний для учеников и их родителей, очень важна личная встреча каждого ученика с директором школы. На данном этапе проводится беседа директора с учеником и его знаконными представителями. Определяются интересы и хобби ученика, склонности к определенным предметам, состояние здоровья, положения и условия в семье. К каждому этапу встречи необходима тщательная подготовка. Например, работа, проводимая до беседы с учащимся и родителями в 7 классе включает следующее:

- Составление графика беседы;

- Отправка анкеты учащемуся и родителям;

- Изучение результатов анкетирования и индивидуальных достижений учащихся в учебе, спорте, научных соревнованиях, олимпиадах (табель; грамоты, дипломы в учебе, спорте и т.п);

- Анализ математической и читательской грамотности Конкурсного отбора;

- Изучение особенностей психологического развития, физического здоровья учащихся.

В приложении 1 указаны примерные вопросы для учащегося 7 класса, задаваемые при беседе. Куратор, психолог и профориентатор принимают во внимание полученную информацию в ходе беседы для формирования личного портрета и составления среднесрочных и долгосрочных целей индивидуального образовательного маршрута ученика (Приложение 2). Эти данные учитываются при выборе элективных курсов, кружков и консультативных занятий для встестороннего развития ученика. Данный этап очень важен для выстраивания доверительных отношений и взаимопомощи между школой, учеником и его родителями.
Для дополнительной помощи, стало традицией прикрепление учеников 11-12 классов к вновь поступившим ученикам 7 классов в качестве наставников, менторов. В рамках проекта «Менің бауырым» (в переводе с казахского «мой младший брат/сестра») учащиеся старших классов оказывают индивидуальную поддержку учащихся младших классов, вовлекают их в культурные, творческие, досуговые мероприятия, помогают в объяснений определенных тем по предмету. Наблюдалось много случаев, когда отношения между ментором и менти становились настолько тесными и теплыми, что учащиеся продолжали общение и по окончанию школы.

Следующая формальная встреча ученика с директором происходит в начале 9 класса, по истечению двух лет обучения в НИШ. При беседе с учеником и его родителями/законными представителями директор имеет всю необходимую информацию: достижения в учебе, творчестве, спорте; активность ученика в школьных проектах, мероприятиях а также инициативах по служению обществу; дисциплина; состояние психологического и физического здоровья; отношения с одноклассниками и т.д (Приложение 3). На данной встрече обсуждаются сильные стороны ученика и области для развития. Основной акцент делается на средний балл успеваемости ученика за период обучения в НИШ.

Согласно ежегодному анализу достижений учащихся, было выявлено, что ученики со средним баллом выше 4,4 имеют хорошие шансы претендовать на место в высших учебных заведениях мирового класса. Однако, контроль по успеваемости каждого ученика и его подготовку нужно проводить как можно раньше (с 8-9 класса), не в страших классах как это обычно делают. Ведь для поступления в международные рейтинговые университеты учащимся не достаточно овладеть предметными знаниями, им предстоит сдавать международные эказмены (SAT, ACT) на английском языке на равне с носителями языка.

Во время личной беседы с директором делается ак- 
цент на «западающие» предметы и составляется индивидуальный маршрут ученика, который включает в себя консультативные и дополнительные занятия по определенным темам. Психологи и школьный врач предлагают рекомендации по составлению сбалансированного режима дня, который должен в себя включать не только академические занятия но и своевременное питание, отдых, занятия спортом и творчеством. Кураторы, учителя, родители, профориентатор и психологи работают вместе для оказания поддержки ученику и достижения его максимального потенциала.

В конце 10 класса проводится третья личная беседа ученика с директором. Данная беседа главным образом носит профориентационный характер, где определяются предметы по выбору для изучения в старших классах (11-12), а также предполагаемые спецальности по которому ученик хотел бы проложить обучение в университете. На основе анализа успеваемости и ранее проведенных бесед с профориентатором а также результатов анкетирований подготавливаются рекомендации для ученика и его родителей. Роль школы объективно оценить возможности ученика и предложить варианты по которому обучающийся может успешно сдать экзамены и поступить на грант по желаемой специальности в стране либо за рубежом.

В старшних классах ведется активная подготовка ученика к международным экзаменам по специально выстроенному индивидуальному плану, которые включают конкретные SMART цели по достижению желаемых результатов.

В конце 11 класса проводится итоговая беседа ученика с директором. У большинства учеников к этому времени имеются в наличи результаты международных экзаменов (IELTS, TOEFL, SAT, ACT). На данной встрече проводится анализ прогресса по индивидуальному маршруту, вносятся необходимые корректировки в задачи и цели ученика. Каждому ученику предоставляется актуальная информация по условиям поступления в вузы, наличие грантов и необходимых документов для зачисления. На «финишной прямой» ученик готовиться к выпускным экзаменам школы (МЭСК-международный экзамен совета Кембриджа) и продолжает сбор портфолио с доказательной базой своих достижений для поступления в вузы.

В результате проведенных анкетирований и интервью среди учеников и родителей было выявлено, что ме- тод личной беседы директора с учениками помог обучающимся правильно выстроить план работы на каждый учебный год и стремится к конкретной и достижимой цели. Учащиеся выразили мнение, что данные беседы придавали им мотивацию и они чувствовали отвественность за свое обучение. Во время интервью один из учеников отметил: «Зная что нам предстоит следущая беседа с директором и анализ нашего прогресса, я старалась выполнять все поставленные задачи в срок и я очень довольна проделанной работой». «Личный контроль самого директора это отличная идея, я заметила, что мой ребенок стал очень организованным и его успеваемость значительно улучшилась»,- высказался один из родителей. В комментариях анкетирования ученики также отметили, что им очень приятно когда директор знает не только школьные достижения учеников но и их интересы, положения дел в семье, интересуется об атмосфере в семье и как поживает тот либо иной член семьи.

На примере НИШ г.Усть-Каменогорск, где в течение 6 лет проводились регулярные беседы ученика с директором, было выявлено, что среди 467 выпускников:

- 100\% поступили в вузы (35 учеников поступили в зарубежные вузы);

- 96\% поступили вузы на грант;

- Средний балл IELTS выпускников выше 6.3;

- Кол-во учеников окончивщие школу со знаком "Алтын белгі" -77 [7].

Стоит также отметить, что только в 2013 году НИш Усть-Каменогорск выпустил самое большое количество выпускников (44), поступивших в Назарбаев Университет, по сравнению с другими школами НИШ, где данный метод не практиковался.

Метод личной беседы директора с учениками требует тщательной подготовки и занимает большое количество времени (Например, в течение 2012 года было проведено 122 встреч с учениками 7х классов, 99 встреч с учениками 9 класса, 149 встреч с учениками 11 класса и 80 встреч с учениками 12 класса). Однако данная работа имеет большое значение для каждого ученика, которые чувствуют личную заинтересованность самого директора в их развитии и достижениях. Благодаря личным встречам с директором, ученики получают мотивацию и направление для их максимального развития. Более того, результаты показывают, что данный подход способствует достижению высоких показателей среди выпускников и успешному зачислению в ведущие вузы страны и мира.

\section{Приложение 1}

\section{Примерные вопросы для учащегося 7 класса, задаваемые при беседе}

1. Опиши свой идеальный день;

2. Что может сделать его особенным?
3. У тебя есть идеи новых изобретений?

4. Какими хорошими качествами обладают твои друзья? 
5. Какими хорошими чертами можешь похвастаться ты?

6. Как думаешь: изучать другой язык - это интересно?

7. Назови три вещи, которые ты хотел бы сделать осенью;

8. Что делает человека умным?
9. Что тебя беспокоит?

10. Какое воспоминание делает тебя счастливым?

11. Ты можешь провести весь день вне дома: что ты будешь делать?

12. Какое явление природы тебе нравится больше всего?

\section{Приложение 2}

\section{Шаблон индивидуальный образовательного маршрута учащегося НИШ на учебный год}

Ф.И. учащегося

Класс

Среднесрочная цель (1 полугодие)

Долгосрочная цель (учебный год)

\begin{tabular}{|c|c|c|c|c|c|c|}
\hline \multirow{3}{*}{ № } & \multicolumn{6}{|c|}{ I полугодие } \\
\hline & \multirow[b]{2}{*}{ Предмет } & \multirow[b]{2}{*}{ Цель } & \multicolumn{2}{|c|}{ Результат ВС0 } & \multicolumn{2}{|c|}{ Действия по улучшению } \\
\hline & & & Макс. балл & Мой балл & $\begin{array}{c}\text { Самостоятельная } \\
\text { работа }\end{array}$ & $\begin{array}{c}\text { Индивидуальная } \\
\text { консультация с учителем }\end{array}$ \\
\hline 1 & Қазақ тілі (т1) / Русский язык (я1) & & & & & \\
\hline 2 & $\begin{array}{l}\text { Казахская литература / Русская } \\
\text { литература }\end{array}$ & & & & & \\
\hline 3 & Русский язык (Т2) / Қазақ тілі (Я2) & & & & & \\
\hline 4 & Английский язык & & & & & \\
\hline 5 & География & & & & & \\
\hline 6 & Математика & & & & & \\
\hline 7 & Информатика (ИКТ) & & & & & \\
\hline 8 & Биология & & & & & \\
\hline 9 & Физика & & & & & \\
\hline 10 & Химия & & & & & \\
\hline 11 & Всемирная история & & & & & \\
\hline 12 & История Казахстана & & & & & \\
\hline 13 & Самопознание & & & & & \\
\hline 14 & Искусство & & & & & \\
\hline 15 & Физкультура & & & & & \\
\hline & & & & & & \\
\hline & & & & & & \\
\hline
\end{tabular}

Средний балл успеваемости за I полугодие / из 5.0

Подготовка к международным экзаменам:

\begin{tabular}{|c|c|c|c|}
\hline № & Наименование экзамена & Мой балл & Моя цель \\
\hline 1 & IELTS & & \\
\hline 2 & SAT & & \\
\hline 3 & & & \\
\hline
\end{tabular}

Подпись ученика Подпись

Подпись куратора 


\section{Приложение 3}

Образец личной карты учащегося

Маратов Ж.К., ученик 10 кл

Будущяя профессия: Генетика, Биомедицина

Результаты IELTS: 6.0 (Следующий срок сдачи: Март)

Сдача SAT: Май

Успеваемость за три класса

\begin{tabular}{|l|c|c|c|c|}
\multirow{2}{*}{\multicolumn{1}{c|}{ Предметы }} & 8кл. & 9кл. & \multicolumn{2}{c|}{ 10кл. } \\
\cline { 2 - 5 } & Годовая оценка & Годовая оценка & Годовая оценка & \\
\hline Казахский язык & 4 & 4 & 4 & \\
\hline Казахский литература & 4 & 4 & 4 & \\
\hline Русский язык & 5 & 4 & 4 & \\
\hline Английский язык & 4 & 4 & 4 & \\
\hline Математика & 4 & 4 & 4 & \\
\hline Информатика & 4 & 5 & 5 & \\
\hline История Казахстан & 4 & 4 & 4 & \\
\hline Искусство & 5 & 5 & 3 & \\
\hline География & 4 & 4 & 4 & \\
\hline Биология & 4 & 4 & 4 & \\
\hline Химия & 4 & 4 & 4 & \\
\hline Физика & 4 & 3 & 4,08 & \\
\hline Всемирная история & 4 & 4,08 & 4 & \\
\hline Средний балл & 4,15 & & 4 & \\
\hline
\end{tabular}

\begin{tabular}{|l|l|}
\hline Личные интересы учащегося, хобби & Биомедицина, Футбол \\
\hline Учебные/академические достижения; & 2 место в региональном проекте по биологии \\
\hline Спортивные и творческие достижения/участие в кружках & $\begin{array}{l}1 \text { место в сети ниш по футзалу, участвует в кружке Globally } \\
\text { Speaking }\end{array}$ \\
\hline Творческие достижения & - \\
\hline Элективные курсы & биомедицина \\
\hline Служение обществу & Волонтер в доме малюток \\
\hline Состав семьи/примечания & $\begin{array}{l}\text { Родители в разводе, мать воспитывает одна, с отцом не поддер- } \\
\text { живают связь, единственный ребенок }\end{array}$ \\
\hline
\end{tabular}

\section{ЛИТЕРАТУРА}

1. Anaya G., Cole D. Latina/o student achievement: Exploring the influence of student-faculty interactions on college grades // Journal of College Student Development. 2001. № 42 (1). Pp. 3-14.

2. Chikering A., Reisser L. Education and Identity 2nd Edition. San Francisco: Jossey-Bass, 1993.

3. Cokley K. An investigation of academic self-concept and its relationship to academic achievement in African American college students // Journal of Black Psychology. 2000. № 26 (2). Pp. 148-164.

4. Rosenthal R., Rosnow R., Rubin D. Contrasts and effect sizes in behavioral research: A correlational approach. New York: Cambridge University Press, 2000.

5. Thompson M.D. Informal Student-Faculty Intraction: Its Relationship to Eductional Gains in Science and Mathematics Among Community College Students // Community 
College Review. 2001. № 29 (1). Pp. 35-57.

6. Wolters C., Rosenthal H. The relation between students' motivational beliefs and attitudes and their use of motivational regulation strategies // International Journal of Educational Research. 2000. Pp. 801-820.

7. NIS Oskemen C. Имиджевый ролик Назарбаев Интеллектуальная школа г.Усть-Каменогорск // Youtube. Дата публикации: 3.01.2018. Режим доступа: https:// www.youtube.com/watch?v=7ggnODrWgc4\&t=281s.

(c) Раисова Кульфарида Бабагумаровна (raisova_k@сpm.kz), Ахметова Анара Кайратовна (akhmetova_a@ukk.nis.edu.kz). Журнал «Современная наука: актуальные проблемы теории и практики»

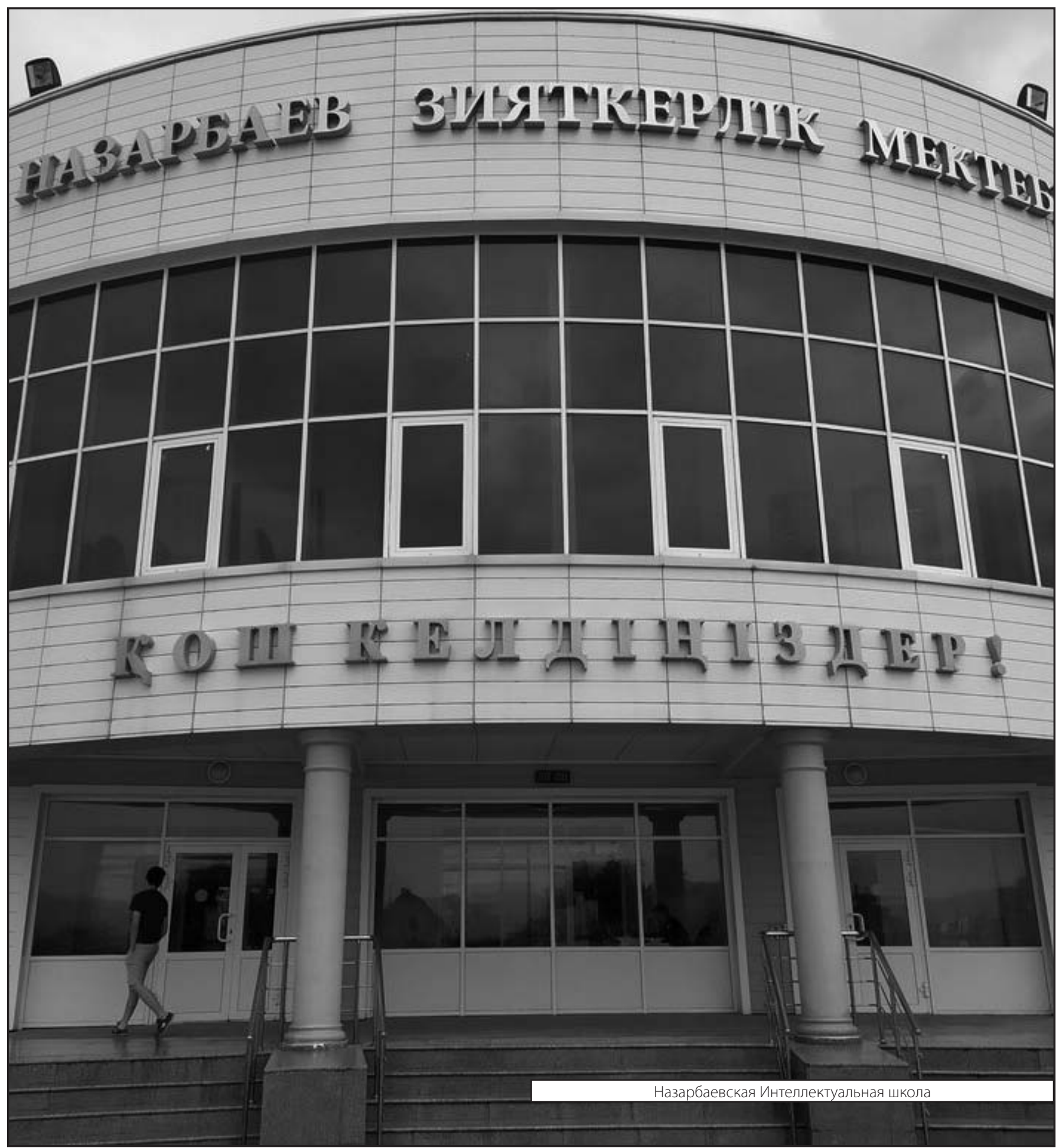

